\title{
Tobacco Control Policies in the Republic of Korea and the Methods of the ITC Korea Surveys
}

Hong Gwan Seo', Yeol Kim², Steve Shaowei $X^{3}{ }^{3 *}$, Anne C. K. Quah", Christian Boudreau ${ }^{4}$, Mi Yan ${ }^{3}$, Mary E. Thompson ${ }^{4}$, Geoffrey T Fong ${ }^{2,5,6}$

${ }^{1}$ Department of Cancer Control and Policy, Graduate School of Cancer Science \& Policy, National Cancer Center, ${ }^{2}$ Division of Cancer Management Policy, National Cancer Center, Goyang, Korea, ${ }^{3}$ Department of Psychology, University of Waterloo, Waterloo, Ontario, Canada, ${ }^{4}$ Department of Statistics and Actuarial Science, University of Waterloo, Waterloo, Ontario, Canada, ${ }^{5}$ School of Public Health and Health Systems, University of Waterloo, Waterloo, Ontario, Canada, ${ }^{6}$ Ontario Institute for Cancer Research, Toronto, Ontario, Canada

Received: November 7, 2017

Revised: January 10, 2018

Accepted : January 11, 2018

${ }^{*}$ Corresponding author :

Steve Shaowei Xu

Department of Psychology,

University of Waterloo,

200 University Avenue West,

Waterloo, Ontario, N2L 3G1, Canada

Tel: 1-519-888-4567 ext 39179

Fax: 1-519-746-8631

E-mail: s4xu@uwaterloo.ca
This article reviews tobacco control policies that have recently been implemented in the Republic of Korea and describes methods of the ITC Korea Surveys conducted from 2005 to 2016 to evaluate the impact of those policies. The ITC Korea Surveys are part of the ITC Project, a large global project being conducted in 29 countries, whose main objective is to conduct rigorous evaluation of tobacco control policies of the WHO Framework Convention on Tobacco Control (FCTC). The ITC Korea Project is a collaboration between the Korean National Cancer Center (NCC) and the ITC Project at the University of Waterloo in Canada. Over 11 years, the ITC Korea research team has conducted two longitudinal surveys of a national cohort of adult smokers in Korea. The first cohort survey was conducted in 2005, 2008, and 2010. In 2016, the first wave of a new cohort survey was conducted. The ITC Korea Project is a critically important evidence system for evaluation of policies that complements the evidence from existing surveillance systems. Evaluation evidence on the impact of FCTC policies is becoming increasingly important to guide actions toward achieving the ambitious objectives of the Sustainable Development Goals and the WHO's Global Action Plan for Prevention and Control of Noncommunicable Diseases. Evaluation evidence is also critically important for governments whose policies are being challenged in domestic and international courts and via trade treaties.

Key Words: FCTC; Tobacco control; ITC Korea survey; Sample design

Copyright (c) 2018 by Journal of the Korean Society for Research on Nicotine and Tobacco.

This is an Open-Access article distributed under the terms of the Creative Commons Attribution Non-Commercial License (https://creativecommons.org/licenses/by-nc/4.0/) which permits unrestricted non-commercial use, distribution, and reproduction in any medium, provided the original work is properly cited.

\section{Tobacco Use and Tobacco Control Polices in the Republic of Korea}

Tobacco smoking constitutes an enormous threat to the health and well-being of the Republic of Korea, accounting for $41 \%$ of all cancers for males and $5 \%$ of all cancers for females. Tobacco use is the country's leading single cause of death, being responsible for 58,000 deaths 
each year. Direct (medical expenses) and indirect (income and productivity) cost attributed to tobacco use was 7,126 billion Korean Won (KRW) in 2013, compared with 409 billion KRW in 2005.(1)

In 2014, smoking prevalence among adults aged 19 and over was $23.3 \%-42.3 \%$ among men and $5.1 \%$ among women.(2) Smoking prevalence has declined significantly since 1998, when $66.5 \%$ of men smoked. Nine years later, in 2007, male smoking prevalence decreased to $45.0 \%$. However, the rate of decline in smoking has been very slow since 2007 (the decrease from $45.0 \%$ in 2007 to $42.3 \%$ in 2014 implies an average decrease of only $0.4 \%$ per year). Among adult women, smoking prevalence has not changed much, varying between $5 \%$ and $7 \%$ over the same period.

In 1995, the Republic of Korea began to enact a few tobacco control regulations in the National Health Promotion Act (NHPA).(3) The NHPA required text-only health warnings on cigarette packs, began the designation of smoke-free areas, restricted tobacco sales, prohibited sales to minors, restricted tobacco advertising, promotion, and sponsorship, and carried out education campaigns to raise the awareness of the harmful effects of smoking.

Korea signed the WHO FCTC in 2003, and the treaty came into force in 2005. Korea increased the tobacco tax by 500 KRW (approximately 0.5 USD) per cigarette pack in 2004.(3) In 2005, nationwide government-supported smoking cessation clinics began to operate in public health centres.

From 2005 to 2014, more tobacco control policies were introduced or strengthened. In 2006, Korea introduced the National Quitline Service consistent with FCTC Article 14 (cessation). In 2009, tax-free cigarettes for soldiers were eliminated. In 2010, after being granted the power to regulate outdoor smoking, some local governments began to restrict smoking in outdoor public areas (FCTC Article 8) such as in bus stops, parks, school clean zones, gas stations, and playgrounds. In 2011, smoking was completely banned in government offices, nurseries, medical facilities, schools, large buildings, and theaters.

By 2014, although advances had been made in tobacco control in several FCTC policy domains, in other domains, there were significant gaps. Perhaps the most important of these was the lack of strong tobacco tax policies (FCTC Article 6), which is widely acknowledged as the most important tobacco control policy domain. $(4,5)$ In Korea, while both inflation and personal income increased, no additional tax increases were introduced, increasing the affordability of cigarettes.(6) In addition, places where smoke-free laws were implemented, described above, were far from comprehensive; notably, there were no smoking bans in key hospitality venues such as restaurants and bars. (7) Tobacco advertisement, promotion, and sponsorship (TAPS) activities (FCTC Article 13) were somewhat restricted but not banned completely as called for under the treaty. In addition, health warnings continued to be small and text-only, with no introduction of pictorial images, as called for under FCTC Article 11. Misleading and deceptive brand descriptors such as "mild" or "light" were still permitted, although Article 11 called for their elimination.

A recent analysis of the impact of strong implementation of the FCTC on reducing smoking prevalence brings into sharp focus the lost opportunities for public health from failing to implement significant policies of the FCTC. In that analysis of 126 countries, those countries that implemented a greater number of these key demand-reduction policies of the FCTC (Articles 6, $8,11,13,14)$ at the highest level experienced a significantly greater reduction in smoking rates: equal to 7.09\% relative decrease in smoking rates for each additional policy implemented over the first decade of the treaty (2005-2015).(8) In the case of Korea, only one policy was fully implemented (cessation: Article 14). If the other 4 policies had been fully implemented, the expected reduction in smoking rates would be $4 \times 7.09 \%$ relative reduction $=28.4 \%$. In other words, the smoking 
rate might have dropped by over one-quarter, putting male smoking prevalence in the mid-30\% rather than at its current $42 \%$.

In recent years, the Korean government has strengthened its efforts to tackle the smoking problem. The National Health Plan 2020 (HP 2020) put forward an objective of reducing the smoking prevalence among adult males to $29 \%$ and among adult females to $6 \%$ by the year 2020.(9) HP 2020 established a path for significant advances in tobacco control. The following FCTC policies were implemented on January 1, 2015:(2)

- There was a significant increase in cigarette taxes and retail prices. From January 1, 2015 and for a pack of 20 cigarettes, the excise tax on cigarettes increased from 1,550 KRW to 3,318 KRW, which increased retail price of the majority of cigarette brands from 2,500 KRW to 4,500 KRW (FCTC Article 6);

- Misleading and deceptive terms such as "mild" or "light" were banned from all tobacco packages (FCTC Article 11)

- All restaurants and bars became smoke-free (FCTC Article 8)

- Tobacco advertising was banned in retail shops (FCTC Article 13)

- Smoking cessation treatment began to be reimbursed by the national health insurance programme (FCTC Article 14)

- 17 local smoking cessation centers were established (FCTC Article 14)

- All cigarettes were required to meet the "reduced ignition propensity (RIP)" standard to reduce their potential for starting fires (FCTC Article 9)

An additional important FCTC policy relating to FCTC Article 11 was implemented on December 23, 2017, when pictorial health warnings were introduced.

\section{Evaluating Tobacco Control Policies}

Because of the recent accelerated implementation of strong tobacco control policies and nearly full integration of the FCTC into Korea's national tobacco control policies, it is important to measure whether these policies have had their intended effects. Are smoke-free laws significantly reducing exposure to secondhand smoke, which accounted for more than 600,000 deaths among non-smokers globally in 2010?(10) Are the new graphic warnings significantly enhancing the communication of the harms of tobacco products? Are these warnings motivating smokers to quit and reducing initiation among non-smokers?

The impact of recent tobacco control polices in Korea was evaluated by the International Tobacco Control (ITC) Korea Project. The ITC Project, centered at the University of Waterloo in Canada, is an international research collaboration across 29 countries - Canada, United States, United Kingdom, Australia, Ireland, Thailand, Malaysia, Republic of Korea, China, Mexico, Uruguay, New Zealand, France, Germany, the Netherlands, Bhutan, Mauritius, Brazil, India, Bangladesh, Kenya, Zambia, Spain, Poland, Hungary, Romania, Romania, Abu Dhabi-United Arab Emirates, and Japan. Together, the ITC Project has conducted evaluation research in countries covering over half of the world's population and over two-thirds of the world's tobacco users, across all six WHO regions and across all four income levels of the World Bank classification.

The primary objective of the ITC Project is to conduct rigorous evaluation studies of the psychosocial and behavioural effects of tobacco control policies of the FCTC. In each of the 29 countries, the ITC Project has conducted large-scale longitudinal cohort surveys to achieve this objective. Beginning in 2002, before the FCTC was adopted, the ITC Project has now conducted over 120 survey waves across the 29 countries. For example, in the original four countries-Canada, United States, United Kingdom, and Australia-there have been 11 waves of the ITC survey among a nationally representative cohort of about 2,000 adult smokers in each of 
the four countries.

In addition to the cohort design of the ITC Project, which allows for rigorous analyses of policy impact at the level of the individual, the ITC survey includes key measures of each FCTC policy domain that are identical or functionally similar across all ITC countries to facilitate cross-country comparisons. Together, the design and content features of the ITC surveys, along with the cross-country comparisons allow for strong quasi-experimental evaluation studies (also known as natural experiments, and "Difference-In-Difference" models in economics). In these evaluation studies, a policy implemented in one country is evaluated by examining changes in policy-relevant variables in that country from pre- to post-policy survey waves in comparison to other ITC countries where that policy has not changed. This research design provides high levels of internal validity, allowing more confident judgments regarding the possible causal impact of the policy. For a description of the conceptual model and objectives of the ITC Project, see Fong et al. (2006);(11) for a description of the survey methods, see Thompson et al. (2006).(12)

\section{The ITC Korea Project}

The ITC Korea Project was created in 2005 as a partnership between the Korean National Cancer Center (NCC) and the ITC Project at the University of Waterloo in Canada to rigorously evaluate the psychosocial and behavioural effects of tobacco control legislation in the Republic of Korea. The Project's overall goal is to provide an evidence base to guide the Korean government on policies enacted under the FCTC and to systematically evaluate the effectiveness of these legislative efforts.

The ITC Korea Project has three main research objectives:

1. To examine patterns of smoking behaviour among adults in the Republic of Korea.
2. To examine the impact of tobacco control policies in the Republic of Korea over time.

3. To compare smoking behaviour and the impact of tobacco control policies between the Republic of Korea and other ITC countries.

The first wave of the ITC Korea (KR1) Survey was conducted in December 2005 (among 1,002 smokers), Wave 2 (KR2) was conducted between October and December 2008 (among 1,818 smokers), and Wave 3 (KR3) was conducted between October and December 2010 (among 1,753 smokers). These three waves of data were collected through telephone interviews by Gallup Korea.

The findings of the three waves of the ITC Korea Survey: 1) documented Korea's slow progress in its tobacco control actions (for health warnings, smoke-free laws, and tobacco taxation) until very recently; and 2) contrasted Korea's tobacco control policies with other countries whose policies have been far more effective. Analyses of data from the first three waves of the ITC Korea Survey led to the publication of 11 journal articles, $(4,13-22)$ over 30 presentations of findings at scientific conferences, and a national report describing the findings from the first three study waves, (23) which was released at the $5^{\text {th }}$ Session of the Conference of the Parties of the FCTC in Seoul in November 2012.

While continuing with the key objectives of the ITC KR Survey and with the new and amended tobacco control policies implemented in 2015, retaining the cohort recruited in KR1-3 was found not to be cost-effective due to an expected very low retention rate given the six years between KR3 and the new survey wave. Thus, a new cohort of 2,000 smokers was recruited for Wave 1 of a new cohort survey, the ITC Korea (KOR1) Survey (with the new name "KOR" used to distinguish the new cohort from the original cohort, “KR”). The ITC KOR1 Survey built on the success of previous ITC KR1-3 Surveys allowing for cross-sectional comparisons, and on the longstanding ITC Project which has involved establish- 
ing longitudinal surveys of other ITC countries allowing for cross-country comparisons and a common mediation model to evaluate the behavioral impacts of national-level tobacco control policies implemented under the WHO FCTC. The summary of Korea's tobacco control policies and survey waves is presented in Figure 1.

To date, tobacco control policy formulation and implementation in Korea have been focused mostly on cigarette smoking. However, in the past few years, especially after the substantial increase in cigarette taxes and thus retail prices in January 2015, there have been concerns that other forms of tobacco use (e.g., waterpipe, chewing tobacco) and of e-cigarettes and other alternative nicotine delivery devices (most recently, with heat-not-burn products, such as iQOS, a Philip Morris International product) may have increased.(24)

The increase in non-cigarette tobacco products and nicotine delivery devices necessitated changes in the complexity of the ITC survey to track transitions in tobacco use over time, including dual-product (e.g., concurrent use of cigarettes and e-cigarettes) or even triple-product patterns (concurrent use of cigarettes, waterpipe, and chewing tobacco). Thus, the 2016 KOR1 Survey (Wave 1 of the new KOR cohort) was constructed with a more complex research design and measures to allow for precise and tailored analyses of transitions of tobacco use and to identify possible causes of those transitions. In addition, a number of new e-cigarette measures were included in the survey to allow for comparisons to the ITC Four Country Tobacco and E-Cigarette Survey, being conducted in Canada, US, England, and Australia and to other ITC countries where e-cigarettes and other alternative nicotine delivery products are increasing in prevalence and consumer awareness.

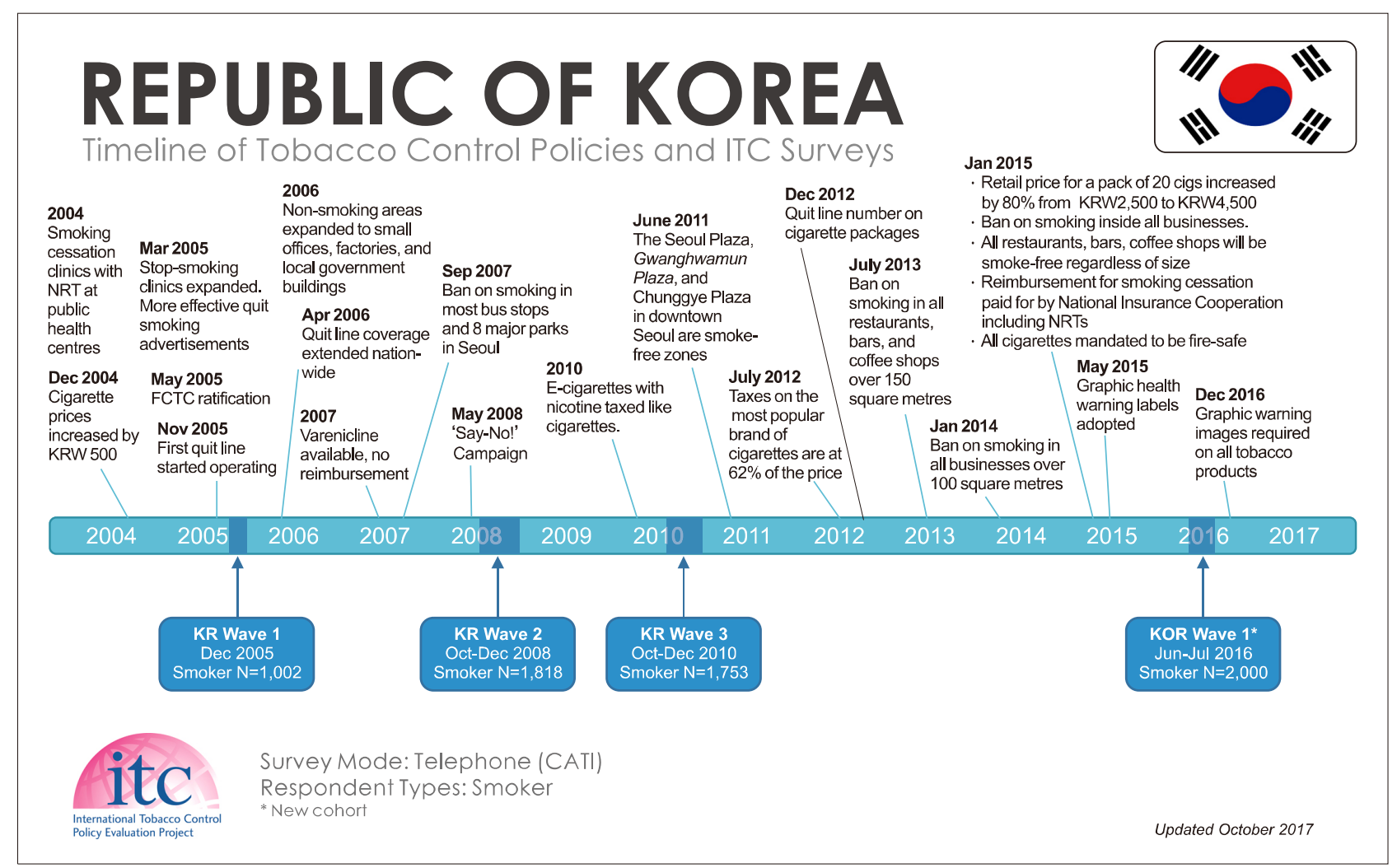

Figure 1. Timeline of Korean tobacco control policies and of the ITC Korea survey waves. 


\section{Sampling Design}

The inclusion criteria for all of the ITC Korea Surveys (ITC KR1-3 and KOR1 Surveys) were the same: respondents were 19 years or older, had smoked more than 100 cigarettes in their life, and smoked at least once in the 30 days prior to being recruited.

For the ITC KR1-3 Surveys, the population was stratified into 16 geographic strata: six metropolitan cities, eight provinces, the national capital of Seoul, and the self-governing province of Jeju. The quotas or numbers of respondents to be sampled in each of the 16 strata were assigned using proportional allocation to the estimated size of the adult population in each of the strata. Within each stratum, households were then randomly called using a random-digit dialling (RDD) and adult smokers interviewed until the corresponding quota was met. This process was repeated independently for each of the 16 strata. In households with multiple eligible respondents, the Next-Birthday method was used to select a single one.(22) No substitution within household was allowed, except when it was known that the selected respondent would be absent for the entire fieldwork period. Each participant was sent an information letter and a voucher for the amount of 10,000 KRW (approximately \$10 USD) as a token of appreciation for responding.

The study sample in KR2 and KR3 included cohort participants from KR1, as well as newly recruited respondents (the replenishment sample) to replace those lost to follow-up. These new participants were selected using the same sampling design as KR1.

The sample size was increased at KR2 from 1,002 to 1,818 respondents. Due to the three-year gap between KR1 and KR2, only 441 respondents from KR1 were successfully re-surveyed (a retention rate of 44.0\%). 1,377 replenishment respondents were interviewed resulting in a total sample size of 1,818 respondents. KR3 consisted of 1,029 respondents from KR2 (the retention rate was $56.6 \%$ ) and 724 replenishment respondents for a to- tal sample size of 1,753 adult smokers and former smokers.

As explained above, because of the long gap between the KR3 survey wave in 2010 and the next wave of the survey, which was planned for 2016, the research team concluded that it would be most cost-effective for the 2016 survey wave to be conducted by the recruitment of a completely new cohort of 2,000 smokers (ITC KOR1). Further information on the KR1-3 and KOR1 methods of the ITC Korea Surveys can be found in the ITC Korea Technical Reports. (26-29)

Unlike KR1-3 Surveys, a dual-frame sampling design was used for the new cohort of KOR1: 1) fixed-line/ landline random digit dialing (RDD), and 2) mobile phone RDD. 2,000 respondents, 423 from the landline frame and 1,577 from the mobile phone frame were sampled according to the seven geographic strata quotas as well as the gender/age quotas, in order to ensure proper presentation of female and male smoker aged 19 to 39 . Landline and mobile phones were then randomly called using RDD until quotas were met. In the mobile phone frame, only the owner/main user of the phone was eligible to be interviewed. Up to two smokers from the same household could be interviewed in the landline frame. Though the sampling design and the survey protocol allowed for up to two individuals from the same household to be recruited and interviewed in the landline frame, none of the 423 respondents recruited via the landline frame came from the same household. This is partially due to the low smoking prevalence among women, but is also likely due to the fact that it is very challenging to convince more than one individual from the same household to complete an hour-long survey.

Table 1 presents the sample sizes, survey dates, and the survey firm for each of the four waves.

Figure 2 presents the composition of the respondents for each of the four survey waves. 
Table 1. Sample sizes, survey dates, and survey firms of the ITC KR1-3 and KOR1 Surveys.

\begin{tabular}{|c|c|c|c|c|c|}
\hline Survey & & Sample size (smokers) & \multicolumn{2}{|c|}{ Survey date } & Survey firm \\
\hline & & 1,002 & \multicolumn{2}{|c|}{ December 2005} & Gallup Korea \\
\hline & & 1,818 & \multicolumn{2}{|c|}{ October - December 2008} & Gallup Korea \\
\hline & & 1,753 & \multicolumn{2}{|c|}{ October - December 2010} & Gallup Korea \\
\hline \multicolumn{2}{|c|}{ KOR1 } & 2,000 & \multicolumn{2}{|c|}{ June - July 2016} & Hankook Research Company \\
\hline & \multicolumn{2}{|r|}{$\begin{array}{l}\text { Initial cohort } \\
\text { ("KR") }\end{array}$} & \multicolumn{2}{|r|}{$\begin{array}{l}\text { New cohort } \\
\text { ("KOR") }\end{array}$} & \\
\hline & $\begin{array}{c}\text { KR1 } \\
\text { Dec } 2005\end{array}$ & $\begin{array}{c}\text { KR2 } \\
\text { Oct-Dec } 2008\end{array}$ & $\begin{array}{c}\text { KR3 } \\
\text { Oct-Dec } 2010\end{array}$ & $\begin{array}{c}\text { KOR1 } \\
\text { Jun-Jul } 2016\end{array}$ & \\
\hline \multirow[t]{2}{*}{ Initial cohort } & $\mathrm{n}=1,002$ & $n=441$ & $n=284$ & $n=2,000$ & \\
\hline & & + & + & & \\
\hline \multirow[t]{2}{*}{ Cohort \#2 } & & $n=1,377$ & $n=745$ & & \\
\hline & & & + & & \\
\hline \multirow[t]{2}{*}{ Cohort \#3 } & & & $n=724$ & & \\
\hline & \pm & $\frac{i}{i}$ & $i$ & $i$ & \multirow{2}{*}{$\begin{array}{l}\text { Figure 2. Composition of the cohorts } \\
\text { for the ITC KR1-3 and KOR1 Surveys. }\end{array}$} \\
\hline Total & $n=1,002$ & $n=1,818$ & $n=1,753$ & $n=2,000$ & \\
\hline
\end{tabular}

\section{Cooperation and Response Rates}

Cooperation and response rates were computed using formulas akin to formulas RR4 and COOP4 from the American Association for Public Opinion Research (AAPOR).(30) The cooperation rates were $71.2 \%$ for KR1, 79.4\% for KR2, and $95.3 \%$ for KR3. The response rates were $14.5 \%$ for KR1, $2.4 \%$ for KR2, and $8.8 \%$ for KR3.

As mentioned above, the ITC KOR1 Survey used a dual-frame sampling design. Hence, separate cooperation and response rates were computed for each frame. For the mobile phone RDD frame, the cooperation rate was $99.8 \%$ and the response rate was $11.6 \%$. However, these two figures need to be viewed with caution since, compared to other ITC surveys, an unusually large portion of people contacted said that they did not smoke. This is further echoed by the fact that there are very few actual refusals. If we use the fact that the overall smoking prevalence in South Korea is around 23\% to treat some of the 30,507 non-eligible individuals as refusals, the response rate decreases to $2.6 \%$ and the cooperation rate decreases to $21.2 \%$.

Successful completion of potential respondents sampled from the landline frame was the result of a two-step process. First, the brief household screener had to be completed, with one (or two) potentially eligible respondents selected. Second, the respondent selected in step one had to confirm his/her eligibility and then needed to complete the smoker survey. At the household level, the cooperation rate was $60.5 \%$ and the response rate was $10.2 \%$. The conditional response rate after being selected in step one was $62.5 \%$, and multiplying the two response rates yields an overall response rate of $6.4 \%$ for the landline frame. As with the mobile frame, these figures need to be viewed with some caution, as some unknown number of individuals said that there was no smoker in their household as a "polite" strategy for refusing to participate further. The cooperation rates and response rates will be lower as a function of the proportion of potentially qualifying respondents who en- 
gaged in such false reporting.

\section{Weight Calculation}

The ITC KR1-3 and KOR1 weights were constructed to correct and adjust for the following: sample misrepresentation caused by unequal sampling probabilities, frame error (i.e., under coverage and multiplicity), nonresponse, and improving precision of estimates through the use of auxiliary information (e.g., smoking prevalence). In addition to adjusting for the number of eligible smokers in the household, the weights were calibrated to smoking prevalence by geographic regions and age groups for the KR 1-3 Surveys and by geographic $\mathrm{x}$ gender $x$ age groups for the KOR1 Survey. The KOR1 weights also took into account the possibility that respondents could have been reached via both the mobile frame and the landline frame.

For the ITC KR1-3 Surveys, only rescaled weights were constructed. In contrast, both rescaled and un-rescaled weights (i.e., inflation weights) were constructed for the ITC KOR1 Survey. The un-rescaled weights sum to the estimated number of smokers in Korea at the time of data collection; in contrast, the rescaled weights are the inflation weights multiplied by a constant to ensure that their sum is equivalent to the sample size. The main reason for this rescaling is to facilitate joint analyses involving data from the ITC KR1-3 and KOR1 Surveys and that of other ITC surveys. Thus, the rescaled weights can be used to estimate population means and proportions/percentages, as well as in various statistical models (e.g., logistic and linear regressions), where age and gender are amongst the covariates, but they cannot be used to estimate population totals (e.g., the total number of daily smokers).

The technical details on weight calculation are available in the ITC Korea Project technical reports. (26-29)

\section{Conclusion}

The ITC Korea Project constitutes a powerful evidence system for the evaluation of tobacco control policies that have been implemented in the Republic of Korea over the past 10 years. There is strong complementarity between the ITC Korea Project and surveillance surveys conducted that focus on tobacco use (e.g., Global Youth Tobacco Survey) or those that include some questions on tobacco use (e.g., Korea National Health and Nutrition Examination Survey, Youth Risk Behaviour Survey).

Those surveillance surveys are constructed to estimate key indicators of tobacco use (e.g., prevalence, history of use, some measures relevant to cessation), but because they are not explicitly constructed to evaluate measures. In contrast, the ITC surveys have both the longitudinal design, and extensive sets of indicators of impact of those policy indicators that have been used extensively by the ITC Project across nearly 30 countries and over 15 years, since before the FCTC became a treaty.

It is increasingly important for governments and the tobacco control and health communities to measure and understand the impact of their tobacco control programs. Several global health initiatives are relying on major contributions from tobacco control to significantly reduce smoking prevalence in order to achieve their objectives, including the Sustainable Development Goals (SDGs) and The WHO Action Plan for Noncommunicable diseases (NCDs). SDGs are a United Nations initiative adopted by the 2015 United Nations General Assembly, where Goal 3: Ensure healthy lives and promote well-being for all at all ages explicitly calls for countries to implement the FCTC,(31) and many of 16 other Goals are directly and indirectly related to tobacco control.(32) The WHO Action Plan for NCDs calls upon countries to relatively reduce their smoking rates by $30 \%$ by 2025.(33)

Finally, we have seen the beginning of a new era of to- 
bacco industry interference to defeat strong tobacco control measures through legal challenges, some of which have used provisions in trade treaties whereby investors (corporations) are allowed to challenge governmental policies and regulations under claims that those measures violate the provisions of those treaties. The first two trade treaty challenges (PMI's challenge of two of Uruguay's tobacco control measures, and the challenge at the World Trade Organization of Australia's plain packaging law) have involved not only challenges based on international law such as the Agreement on Trade-Related Aspects of Intellectual Property Rights (TRIPS) and General Agreement on Tariffs and Trade (GATT), but also based on claims that the tobacco control measures are not effective. For both countries, evidence from evaluation studies have been instrumental for countries in their defense, and in both countries, ITC Project data have contributed to the defense of these policies being challenged. Countries that have evaluation data demonstrating the effectiveness of their tobacco control policies stand in a better position to defend their policies from such challenges.

\section{References}

1. Ministry of Health and Welfare. 2016 Republic of Korea's Party Report on Implementation of WHO FCTC. MOH. 2016. Available from: http://apps.who.int/fctc/implementation/database/sites/implementat ion/files/documents/reports/rok_2016_report.pdf. Accessed 2017 Oct 23.

2. Seo HG. Helping smokers to quit in Korea. Presented at the $11^{\text {th }}$ APACT Conference on Tobacco Health, Beijing, China. 2016.

3. Cho H-J. The status and future challenges of tobacco control policy in Korea. J Prev Med Public Health 2014; 47: 129-35.

4. IARC. IARC Handbooks of Cancer Prevention: Tobacco Control. Volume 14. Effectiveness of price and tax policies for control of tobacco. Lyon, France: International Agency for Research on Cancer; 2011.

5. Chaloupka FJ, Strait K, Leon, ME. Effectiveness of tax and price policies in tobacco control. Tob Control 2011; 20: 235-8.

6. Park E, Park S, Cho S, Kim Y, Seo HG, Driezen P, et al. What cigarette price is required for smokers to attempt to quit smoking? Findings from the ITC Korea Waves 2 and 3 Survey. Tob Control 2015; 24(Suppl 3): iii48-iii55.
7. Kim SJ, Han K-T, Lee SY, Chun S-Y, Park E-C. Is secondhand smoke associated with stress in smokers and non-smokers? BMC Public Health 2015; 15: 1249.

8. Gravely S, Giovino GA, Craig LV, Commar A, d'Espaignet ET, Schotte $\mathrm{K}$, et al. Implementation of key demand-reduction measures of the WHO Framework Convention on Tobacco Control and change in smoking prevalence in 126 countries: an association study. Lancet Public Health 2017; 2: e166-174.

9. Ministry of Health and Social Welfare. 3rd National Health Promotion Plan (2011-2020). Seoul, Korea: MOH. 2011.

10. Eriksen M, Mackay J, Schluger N, Gomeshtapeh F, Drope J. The tobacco atlas. 5th ed. Atlanta: American Cancer Society; 2015.

11. Fong GT, Cummings KM, Borland $R$, Hastings $G$, Hyland A, Giovino GA, et al. The conceptual framework of the International Tobacco Control (ITC) Policy Evaluation Project. Tob Control 2006; 15(Suppl 3): 3-11.

12. Thompson ME, Fong GT, Hammond D, Boudreau C, Driezen P, Hyland $A$, et al. Methods of the International Tobacco Control (ITC) Four Country Survey. Tob Control 2006; 15(Suppl 3): 12-8.

13. Seo HG, Cheong Y, Myung SK, Kim Y, Lee WB, Fong GT. Smoking-related characteristics in Korean adult smokers: findings from the 2005 International Tobacco Control Policy Evaluation Survey Korea. J Korean Acad Fam Med 2008; 29: 844-53.

14. Kwak SM, Seo HG, Myung SK, Kim Y, Jung HS, Fong GT, et al. Analysis of smoking-related characteristics over time in Korean adult smokers: findings from the International Tobacco Control (ITC) Korea Survey. Korean J Fam Practice 2011; 1: 192-203.

15. Borland R, Li L, Driezen P, Wilson N, Hammond D, Thompson ME, et al. Cessation assistance reported by smokers in 15 countries participating in the International Tobacco Control (ITC) policy evaluation surveys. Addiction 2012; 107: 197-205.

16. Myung SK, Seo HG, Cheong Y, Park S, Lee ES, Fong GT. Association of socio-demographic factors, smoking-related beliefs, and smoking restrictions with intention to quit smoking in Korean adults: findings from the ITC Korea Survey. J Epidemiol 2012; 22: 21-7.

17. Sansone N, Fong GT, Lee WB, Laux F, Sirirassamee B, Seo HG, et al. Comparing the experience of regret and its predictors among smokers in four Asian countries: findings from the ITC Surveys in Thailand, South Korea, Malaysia, and China. Nicotine Tob Res 2013; 15: 1663-72.

18. Shang C, Chaloupka FJ, Zahra N, Fong GT. The distribution of cigarette prices under different tax structures: findings from the International Tobacco Control Policy Evaluation (ITC) Project. Tob Control 2014; 23(Suppl 1): 23-9.

19. Tauras JA, Chaloupka FJ, Fong GT, Quah ACK. The economics of tobacco control: evidence from the International Tobacco Control (ITC) Policy Evaluation Project. Tob Control 2014; 23(Suppl 1): i1-3.

20. Gravely S, Fong GT, Cummings KM, Yan M, Quah ACK, Borland R, et al. Awareness, trial, and current use of electronic cigarettes in 10 countries: findings from the ITC Project. Int J Environ Res Public Health 2015; $12: 4631-7$.

21. Shang C, Chaloupka FJ, Fong GT, Thompson ME, O'Connor RJ. The 
association between tax structure and cigarette price variability: findings from the International Tobacco Control Policy Evaluation (ITC) Project. Tob Control 2015; 24(Suppl 3): iii88-iii93.

22. Green A, Fong GT, Borland R, Ouah ACK, Seo HG, Kim Y, et al. The importance of the belief that "light" cigarettes are smoother in misperceptions of the harmfulness of "light" cigarettes in the Republic of Korea: a cohort study. BMC Public Health 2015; 15: 1108.

23. ITC Project. ITC Korea National Report: Findings from the Wave 1 to 3 Surveys (2005-2010) Background and Key Findings. Waterloo, Canada; University of Waterloo; Republic of Korea; National Cancer Center, Korean Association on Smoking or Health. 2012.

24. Lee JA, Kim SH, Cho HJ. Electronic cigarette use among Korean adults. Int J Public Health 2016; 61: 151.

25. Binson D, Canchola JA, Catania JA. Random selection in a national telephone survey: a comparison of the Kish, next-birthday, and last-birthday methods. J Official Stats 2000; 16: 53-9.

26. ITC Project. ITC Korea Wave 1 (2005) Technical Report. Waterloo, Canada; University of Waterloo; Republic of Korea; National Cancer Center, Korean Association on Smoking or Health. 2008.

27. ITC Project. ITC Korea Wave 2 (2008) Technical Report. Waterloo, Canada; University of Waterloo; Republic of Korea; National Cancer
Center, Korean Association on Smoking or Health. 2009.

28. ITC Project. ITC Korea Wave 3 (2010) Technical Report. Waterloo, Canada; University of Waterloo; Republic of Korea; National Cancer Center, Korean Association on Smoking or Health. 2011.

29. ITC Project. ITC Korea Survey Wave 1 (new cohort) Technical Report. Waterloo, Canada; University of Waterloo; Republic of Korea; National Cancer Center. 2017.

30. American Association for Public Opinion Research. Standard definitions: final dispositions of case codes and outcome rates for surveys, 9th ed. AAPOR. 2016.

31. United Nations General Assembly. Transforming our world: the 2030 agenda for sustainable development. UN. 2015.

32. WHO Regional Office for Europe. Tobacco Control \& The Sustainable Development Goals. Available from: http://www.euro.who.int/ data/assets/pdf file/0020/340193/TOBACCO-CONTROL-AND-THE-S USTAINABLE-DEVELOPMENT-GOALS Edited.pdf. Accessed 2017 Oct 23.

33. World Health Organization. Global action plan for the prevention and control of noncommunicable diseases 2013-2020. Geneva, Switzerland; WHO. 2013. 